\title{
PARESIS OF UPPER MOTOR NEURONE TYPE FOLLOWING HERPES ZOSTER
}

\author{
By \\ C. WORSTER-DROUGHT AND W. H. MCMENEMEY, \\ LONDON
}

Paralysis accompanying or following herpes zoster is comparatively infrequent although examples have from time to time been recorded. As a rule the paralyses are of the lower motor neurone type and may be classified according to their anatomical situation. Those most commonly met with are the oculo-motor, the facial, the brachial and the abdominal varieties. Crural paralysis is very rare, and only two cases appear so far to have been recorded. Hardy, ${ }^{1}$ in 1876 , reported a case in which atrophy of the calf muscles followed an attack of zoster. The eruption was situated over the course of the sciatic nerve. It extended throughout the whole length of the limb and lasted for 20 days, but the pain persisted longer. Four to six weeks from the beginning of the illness, there developed a complete amyotrophy of the muscles of the calf and of the external parts of the leg. Some degree of recovery eventually took place. Cornil ${ }^{2}$ recorded the second case in a woman aged 58. Fifteen days after an attack of herpes zoster, which was confined to the thigh, atrophy of the muscles of the thigh was observed. The knee-jerk was completely abolished. Slight recovery of function took place but some atrophy and paresis persisted.

Cases of involvement of the upper motor neurone are rarely met with. Dumery (quoted by Baudouin and Lantuéjoul ${ }^{3}$ ), in 1896, noted a left hemiplegia following four weeks after a herpes zoster confined to the ophthalmic division of the right fifth nerve in a migrainous subject. Brissaud, ${ }^{4}$ in 1890, referred to three cases of crossed hemiplegia in patients with ophthalmic or facial zoster. Bruce, ${ }^{5}$ in 1907 , described an unusual case in a woman aged 54. The rash was confined to the distribution of the seventh and eighth dorsal segments of the right side. Just over three weeks later, when the cutaneous lesions had healed, she noticed weakness and numbness of the right leg, and on examination she showed signs of involvement of the pyramidal tract on the right side together with an ipsolateral dissociated anæsthesia below the level of the rash. In addition, the patient had noticed an absence of sweating in this area. Three weeks later the left lower extremity was found to be involved in exactly the same way as the right. Gradual recovery followed and the patient was left with no disability other than troublesome paræsthesia in the lower limbs. Objectively there remained an undue briskness of the knee-jerks but no other abnormality. Karman, ${ }^{6}$ in 1928, described a case 
of unusual interest. The patient was a woman aged 59. For a year she had complained of pains in the lower lumbar region of the right side. She then developed the rash of herpes zoster over the distribution of the right sixth dorsal segment and this was followed shortly by paræsthesia in the right leg and astereognosis. Both legs became weak and by the end of the eighth week double incontinence had supervened. She complained of radicular pains accentuated by coughing and sneezing. There was tenderness on pressure over the fifth and sixth dorsal vertebræ and a spastic paraplegia with complete sensory loss, both exteroceptive and proprioceptive, below the level of the sixth dorsal segment. The cerebro-spinal fluid was reported to be normal in all respects and no block was demonstrable by the method of Quickenstedt. $\mathrm{X}$-ray examination of the spine and spinal lipiodol were also negative. Laminectomy was performed over the third to fifth dorsal vertebræ and an intradural cyst was found at the level of the sixth dorsal segment (fourth dorsal vertebra). This was evacuated but the patient unfortunately died of septic meningitis and no post-mortem was available. Alajouanine and Bernard Griffith, ${ }^{7}$ in 1931, described an interesting case in a female aged 26. At the age of $\mathbf{1 7}$ she had an eruption of herpes zoster on the right thigh in the distribution of the fourth lumbar segment. There was pain in this area but the illness was afebrile. Fifteen days later she experienced a temporary paresis of the right leg which improved considerably within eight days and had recovered completely at the end of three months. At the age of 21, she had a return of the pain in the right leg and of difficulty in walking. Two years later, at the age of 23 , she exhibited typical signs of disseminated sclerosis.

\section{PERSONAL GASE}

The patient, a male aged 58 years, developed herpes zoster in November, 1929. The eruption occurred without premonitory symptoms and involved the seventh thoracic segment on the left side; it was very profuse and extended almost continuously from the spine behind to the mid-line of the abdomen in front. The skin lesions followed the usual course but as they healed the patient complained of severe pain in the area involved, together with a sense of discomfort in that part of the abdomen lying below the herpetic zone. Three weeks later, cutaneous anæsthesia and analgesia were present over the area affected by the herpes-mainly the left seventh thoracic segment-and the pain continued with varying intensity. Six weeks after the onset of the rash he began to complain of severe pain in the left leg, together with inability to lift the limb. Muscular weakness of the left leg with increased deep reflexes was present but cutaneous sensation apparently normal; the right leg was unaffected and sphincter control was normal. X-ray examination of the spine showed no abnormality and the blood Wassermann reaction was negative. The pain in the herpetic area and in the leg both gradually disappeared, but the patient continued to complain of some hyperæsthesia of the left side of the abdomen in its upper part with a sense of numbness below. The weakness of the left leg slowly improved and at no time did the right leg show any abnormality. His condition when seen six months after the onset of the rash was as follows :-

A zone of cutaneous hyperæmia about 3 inches in width with slight patchy desquamation was still present over the site of the former herpes, extending from 
within an inch of the spine behind to the midline in front, and corresponding to the total area supplied from the seventh thoracic segment.

Sensation : Cutaneous sensation over the above area was impaired to all stimuli. Elsewhere, including the skin of the abdomen below this level and over both legs, cutaneous sensation was normal. Vibration sense was impaired and shortened in duration over the patella, anterior surface of tibia and both malleoli in the left leg, but normal elsewhere.

All cranial nerves including the fundus oculi were normal.

There was distinct weakness on contraction of the abdominal muscles on the left side below the level of the seventh thoracic segment and particularly just below the herpetic area. The abdominal reflexes on the right side were brisk, but they were absent on the left side. The left leg was somewhat spastic and all muscular movements, though present, were diminished in power especially flexion at the hip and dorsiflexion at the ankle. There was no apparent wasting. The left knee and ankle jerks were greatly increased as compared with the right, which were rather sluggish but improved with reinforcement. Left ankle clonus of abortive type. Plantar stimulation gave a strong flexor response on the right side but an indefinite extensor reflex on the left, while Oppenheim's reflex was extensor on this side. Co-ordination in both legs was fairly good and Romberg's sign negative.

Other Systems : Heart and lungs normal ; palpable arteries in good condition ; pulse 76 regular; blood-pressure 160/90. Liver and spleen impalpable; urine no abnormality.

The cerebro-spinal fluid was clear, colourless and under normal pressure. The number of cells per c.mm. was 4 ; they were all small lymphocytes. Total protein 0.025 per cent. No excess of globulin. Lange and Wassermann reactions negative.

Two months later the patient was seen again and found to be walking much better. He still complained of a continual ache on the left side over the zone of the zoster and passing through to the back. All movements of the limbs were good including dorsiflexion of the hip and ankle, but there was a slight reduction in the power of all muscle groups of the limb. There was some impairment to light touch over the former herpetic area, which now showed scars. The deep reflexes of the left leg were still brisker than those of the right and the abdominal reflexes were diminished on the left. The left leg felt colder than the right but both dorsalis pedis and posterior tibial pulses were normal.

Six months later he was seen again (now 14 months after the onset of the rash). He still complained of aching on the left side and that his left leg would give out after walking for about a mile; also that it would ache on exertion. The signs were almost as they were six months previously with the exception that the degree of spasticity was decidedly less. He has been seen again recently, now three and a half years after the onset of the rash. He remains much the same but is now able to walk further. An undue briskness of the deep reflexes of the left leg still persists.

\section{DISGUSSION}

Within recent years there have appeared several valuable papers on the pathology of herpes zoster. In particular we would mention those of Lhermitte and Nicholas, ${ }^{8}$ and 9 Fauré Beaulieu and Lhermitte, ${ }^{10}$ Lhermitte and Vermès, ${ }^{11}$ and Favre and Dechaume. ${ }^{12}$ These authors emphasize the fact that the pathology is essentially a myelitis, the bulk of the changes being in the region of the posterior horn but that similar changes can occur either in the cord, medulla or brain. This is in contradistinction to the theory previously held, that of von Bärensprung ${ }^{13}$ and of Head and Campbell, ${ }^{14}$ that the essential lesion is an inflammation of the posterior root ganglion or 
of their analogues - the cranial nerve ganglia. The modern view, therefore, is to regard herpes zoster as being primarily an acute posterior poliomyelitis, and further in support of this we have the occasional occurrence of a lymphocytosis early in the disease. In these circumstances, it is easy to see that the pyramidal tracts may occasionally be involved in the disease process.

In our case, the inflammation evidently spread from the posterior horn towards the lateral column and involved the motor fibres on their way downwards in the spinal segment concerned. The posterior columns also appear to have been affected to a slight extent as indicated by the impaired vibration sense, but no central grey matter was implicated as common sensation below the level of the lesion on both sides was normal.

In Bruce's case, the fact that the motor and sensory changes were on the same side of the body, indicates that the path for common sensation was involved before it had crossed to the opposite side of the cord. Moreover, the patient had noticed an absence of sweating in the parts affected, and Bruce attributed this to involvement of the intermediolateral tract. To account for these changes, Bruce suggested an inflammatory thrombosis of the postero-lateral or posterior cornual arteries, or perhaps the midcornual branch of the central artery. The subsequent extension to the other side in his case was accounted for by postulating the same changes on the other side of the cord.

As no case resembling either our own or Bruce's case has come to autopsy, the underlying pathology must needs be a matter for speculation. It is reasonable, however, to assume that the inflammatory process spreads from the posterior horn into the neighbouring structures. One would expect a considerable degree of recovery, as indeed occurred in both these cases, when the inflammatory process undergoes involution. Were the cause of the symptoms and signs thrombosis of the vessels, one would expect a lesser degree of recovery because the spinal arteries are end arteries.

Quite apart from giving rise to signs of spinal cord involvement, herpes zoster may also occur symptomatically as an expression of disease of the cord. Thus, in the case of Alajouanine and Bernard Griffith, to which reference has already been made, the herpes zoster apparently coincided, both in time and situation; with the first attack of a disseminated sclerosis. In Karman's 6 case, the herpes zoster coincided with the early symptoms of a spinal cord tumour. The other possibility in this interesting case, as Karman suggested, is that the intradural cyst was the result of the inflammatory process, i.e. secondary to the herpes zoster. There are also in the literature other interesting examples of herpes zoster coinciding with disease of the spinal cord. Schubach ${ }^{15}$ has described herpes zoster in association with Landry's paralysis in a woman aged 62. Marinesco ${ }^{16}$ also reported a zoster of the gluteal region with hyperacute myelitis of the conus medullaris in a man aged 36. The attack followed the seventh injection of a gonococcal vaccine which he was receiving for a urethritis acquired at the age of 22 . It is of interest to note 
that this patient had had an acute anterior poliomyelitis at the age of five which had left him with a lower motor neurone paralysis of the left lower extremity. Becker ${ }^{17}$ has described zoster coinciding with polyneuritis, the result of bismuth therapy in the treatment of syphilis. It would always seem advisable, therefore, in any case of herpes zoster to bear in mind the possibility that zoster may be symptomatic of some underlying disease of the central nervous system.

\section{REFERENCES}

1 HARDy, M., Gaz. des H6pit., 1876, 49, 827.

2 Cornil, L., Rev. Neurol., 1930, 37, 280.

3 Badouin, E., and Lantú́soul, P., Gaz. des Hopit., 1919, 92, 1293.

4 Brissaud, A., Journ. de Med. and Chir., 1896, 6\%, 209.

5 Bruce, A., Rev. Neurol. and Psychiat., Edin., 1907, 5, 885.

6 Karman, G. A., Jour. Amer. Med. Assoc., 1928, 91, 320.

7 Alajouanine, T., and Griffith, B., Rev. Neur., 1931, 38, 84.

8 Lhermitte, J., and Nicholas, M. Rev. Neurol., 1924, 31, 361.

๑ Lhermitte, J., and Nicholas, M., L'Encephale, 1927, 22, 245 and 313.

10 Fauré-Beaulieu, and Lhermitte, J., Rev. Neurol., 1929, 36, 1250.

11 Lhermitte, J., and Vermès, V., Rev. Neurol., 1930, 37, 1231.

12 Favré, M., and Dechaume, J., Lyon Med., 1926, 147, 553.

13 Bärensprung, A., Ann. des Char. Krankht., 1861, 9, 41.

14 Head, H., and Campbell, H., Brain, 1900, 23, 353.

15 Schubach, A., Zeitschr.f. d. g. Neurol. u. Psych., 1930, 123, 424.

16 Marinesco, G., Bull. et Mem. Soc. des Hôpit. de Pai is, 1931, 47, 1735.

17 Becker, S. W., Amer. Jour. Syph., 1932, 16, 313. 